\title{
Devires e intensidades do coletivo na Saúde Coletiva
}

| ${ }^{1}$ Cristian Fabiano Guimarães, ${ }^{2}$ Rosane Azevedo Neves da Silva |

Resumo: Neste artigo, problematizamos o coletivo na saúde, com a finalidade de acompanhar como ele se expressa e quais sentidos atualiza. Situamos nossa investigação em uma perspectiva genealógica, analisando a composição e a perda de sentido dos territórios reformistas nos cenários italiano e brasileiro. Discutimos as imagens para expressar o coletivo na saúde - a população, o grupo e a sociedade civil -, para propor um modo diferente de pensar essa expressão, de caráter processual e intensivo, como potência. Não é a fixação dessa noção às formas atribuídas que afirma a Saúde Coletiva, mas a força que caracteriza o coletivo como algo inespecífico, variação da potência. Considerar a singularidade do coletivo evita que, paradoxalmente, se reproduza uma política que afirme os preceitos da Medicina Social ou da Saúde Pública no campo da Saúde Coletiva, abrindo a possibilidade para novas produções de sentido.

> Palavras-chave: coletivo; Saúde Coletiva; epistemologia; genealogia; reforma sanitária.
1 Programa de Pós-Graduação em Saúde Coletiva, Universidade Federal do Rio Grande do Sul. Porto Alegre-RS, Brasil (crisfabianog@gmail.com).

${ }^{2}$ Instituto de Psicologia, Universidade Federal do Rio Grande do Sul. Porto Alegre-RS Brasil (rosane.neves@ufrgs.br).

Recebido em: 06/01/2016 Aprovado em: 22/04/2016 
Este manuscrito discute o coletivo na saúde. A definição de coletivo e sua aproximação à saúde não são tão simples quanto parecem, pois essa expressão introduz uma série de questóes a serem discutidas. De modo geral, a noção de coletivo é utilizada de forma naturalizada, pois parece que o problema introduzido por essa expressão não foi suficientemente explorado na Saúde Coletiva. Partindo da ideia de que, sem a devida problematização, o coletivo pode ser facilmente vulgarizado ou utilizado como "clichê" - pois, com um significado incerto, essa noção pode se adaptar bem a quaisquer situações -, convém prestar atenção à diferença que esse conceito introduz, especialmente a partir da invenção de um conhecimento que coloca em evidência essa expressão: a Saúde Coletiva.

A discussão é pertinente, pois o coletivo é tomado como sinônimo de conceitos que habitam há muito tempo o território da saúde, como, por exemplo, o público e a sociedade. Se o coletivo fosse sinônimo destes, não haveria necessidade de constituir um campo de conhecimentos e de práticas denominado "Saúde Coletiva", pois a Saúde Pública já se ocuparia do público e a Medicina Social, da sociedade (DONNANGELO, 1975; 1976; FLEURY TEIXEIRA, 1985; 1987; MERHY, 1987). É possível que, tomando o coletivo como um de seus sinônimos, ou seja, sem levar em conta a questão que essa noção coloca para a saúde, a Saúde Coletiva exprima conteúdos da Saúde Pública e da Medicina Social, ambas criticadas pelos teóricos reformistas nos anos 1970 (FLEURY TEIXEIRA, 1992; COSTA, 1992; COHN, 1989; 1992; ELIAS, 1993; ESCOREL, 2009; LUZ, 1991).

Utilizamos como campo problemático os cenários reformistas italiano e brasileiro, uma vez que o movimento reformista brasileiro foi influenciado pela produção italiana (COHN, 1989). Revisitando esses processos de reformas sanitárias, buscamos entender os sentidos atribuídos ao coletivo na saúde, analisando as lutas e as disputas que as agitações políticas da segunda metade do século XX representaram para a invenção da Saúde Coletiva. Do estudo realizado, foi possível depreender duas provocações ou argumentos que sustentam a discussão sobre o coletivo na saúde: a primeira diz respeito à ideia de variação e a segunda, ao inespecífico. Apresentaremos esses argumentos e, em seguida, discutiremos a forma como nossa investigação foi montada. Por fim, teceremos algumas consideraçóes com o intuito de sugerir aspectos que consideramos importantes para avançar na produção de conhecimento sobre esse tema. 


\section{As variações ou a variação do coletivo na saúde?}

$\mathrm{O}$ primeiro argumento pode ser retirado da ideia de que o coletivo varia na saúde. Por que afirmar essa variação? A análise realizada fez aparecer a hipótese de que é preciso olhar para essa expressão não como uma forma fixa, mas como processualidade.

Enquanto processualidade, o coletivo dispara uma força de variar que provoca mudanças no território da saúde, abrindo a possibilidade para a invenção de novos saberes. Para aprofundar a discussão, elaboramos a análise das lutas e das disputas pela noção de coletivo na saúde, prestando atenção ao modo como essa expressão aparecia na Medicina Social e na Saúde Pública, com a finalidade de perceber quais as diferenças que existiam na maneira como a Saúde Coletiva toma o coletivo. Esse movimento foi necessário para compreender o que cada uma das formas de entender o coletivo produz e os efeitos que elas põem em prática em cada um desses saberes tradicionais da saúde.

"Medicina Social" e "Saúde Pública" são termos que tomam forma na saúde num cenário no qual há uma disputa de forças desenhando uma nova arte de governar (FOUCAULT, 2011a; 2011b; 2011c; 2011d). Considerando que ambas foram conhecimentos produzidos com base no pensamento liberal - à luz da economia política -, e que assimilaram uma noção de coletivo instituída que se confunde com o público, o social ou a sociedade (entendida como conjunto ou totalidade que deve ser regulada pelo Estado), podemos perceber que o coletivo como potência aparece como alternativa para analisar a força da Saúde Coletiva, denunciando processos de subjetivação instituídos pelas imagens que essa noção carrega na saúde.

Atentar para a característica singular da noção de coletivo na saúde nos fornece uma pista para estabelecer a diferença entre Medicina Social, Saúde Pública e Saúde Coletiva, questão- chave para entender a invenção desta como campo de saberes e práticas. $\mathrm{O}$ coletivo como potência parece desencadear processos instituintes que induzem rupturas no território da saúde.

Tanto na Medicina Social quanto na Saúde Pública, as imagens do coletivo instituído eram utilizadas com o intuito de construir o indivíduo medicalizado, cujo desejo está orientado para responder à normalização imposta pelo saber médico. A variação do coletivo permite, portanto, sublinhar a diferença que distingue a Saúde Coletiva da Saúde Pública e da Medicina Social, fazendo dessa 
diferença uma força de efetuação da potência do coletivo no plano do pensamento e das práticas em saúde na atualidade.

$\mathrm{Na}$ aposta que a Saúde Coletiva faz no final dos anos 1970 no contexto brasileiro, entendida como esforço de democratização da saúde, paralelamente, também se afirmava um projeto político distinto daquele gestado pelo movimento sanitário, mais próximo dos sentidos políticos afirmados pela Medicina Social: o coletivo instituído, entendido como a "população construída de cidadãos, os homens que cumprem os seus deveres" (MACHADO et al., 1978, p. 255).

Portanto, é preciso estabelecer uma diferença entre duas formas distintas de entender o coletivo na saúde. Para tanto, sublinhamos a tensão que existe entre o coletivo instituído e o coletivo como potência. Passamos a denominar coletivo instituído as variações ou imagens que a noção sofre na saúde, enquanto forma fixa. O coletivo como potência, por sua vez, expressa um modo de entender essa noção que toma a ideia de variação como afirmação da potência. Dito de outro modo: o coletivo enquanto imagem é a forma instituída da noção de coletivo no território da saúde; quando essa expressão varia, estamos chamando a atenção para a sua processualidade instituinte. Duas direções de pesquisa distintas, abertas pela análise do coletivo na saúde: uma que atenta ao plano das formas do coletivo, ou seja, para suas variações em termos de imagens, e outra que presta atenção no coletivo como dimensão intensiva, o plano das forças que variam produzindo diferença.

Analisando as variações que o coletivo instituído assume na saúde, percebemos que discutir essa noção atribuindo a ela uma forma ou uma imagem definida nos impede de analisá-la do ponto de vista da potência que ela introduz na saúde. Desse modo, a ideia de variação torna-se um operador conceitual importante na discussão, pois permite fazer aparecer essas duas dimensões de análise do problema introduzido pela expressão do coletivo na saúde. A forma como fazemos uso da ideia de variação, através do auxílio de alguns autores como Espinoza, Negri e Deleuze (ESPINOZA, 1973; 2009; DELEUZE, 2010; 2002a; 2014; NEGRI, 1993; 2003; 2002), teve como finalidade chamar a atenção para uma dimensão da noção de coletivo ainda pouco explorada na saúde, qual seja, a ideia de coletivo como potência, enquanto processualidade e dimensão intensiva.

Esse percurso inicial conduziu à sistematização das formas que o coletivo assume na saúde, ou seja, o coletivo instituído. As formas do coletivo tradicionalmente utilizadas na saúde são a população, o grupo e a sociedade civil. 
O coletivo-população é a imagem mais comum do coletivo na saúde. Para

entender seu problema, recorremos a Foucault. Sobre o discurso da população, o público é traduzido como o espaço político real, e somente nesse espaço existe a possibilidade de exercício da luta. A dimensão do político está subordinada ao público, assumindo um caráter conservador. Trata-se de um coletivo organizado pela razão de Estado (FOUCAULT, 2008).

Espinoza (2009) contribuiu para permitir compreender como se instituiu o domínio do público e a relação entre essa expressão e o Estado, além de permitir entender seu aspecto constitutivo. O conceito espinozista de multitude é uma pista para compreendermos como a potência do coletivo é capturada pela população, ou seja, transformada num modo de entender o público que encontra na população a sua forma ideal de expressão. A multitude é o elemento instituinte do Estado Moderno, constituindo-o em termos de pensamento e em extensão. O pensamento corresponde ao desenvolvimento da razão e sua extensão à dimensão do público. A multitude e a sua potência - o seu desejo - colocam o Estado enquanto devir, criando as condições para que ele se desenrole sobre o espaço público, juntamente com o desenvolvimento da razão. Foucault (2008) ajuda a entender como foi se compondo um saber sobre o público, discutindo a razão de Estado, onde podemos localizar a ligação entre público e população. O público, objeto da Medicina Social ou da Saúde Pública é, portanto, um espaço a ser povoado e tornado concreto. Ele é o plano sobre o qual a razão de estado se desenvolverá, no sentido de objetivar aquilo que é comum, ou seja, o que se produz com a instituição de um "estado civil" e que diz respeito ao indivíduo e à vida em sociedade.

A noção de público aparece, portanto, como aquilo que deve ser gerido, investido, tensionado, mas também cultivado, haja vista que da sua constituição advêm o Estado e sua função de conservar a existência em comum, onde todos possam, juntos, atingir os seus objetivos individuais. Constituído enquanto propriedade de muitos, o público deve ser capitalizado. Está na sua base a ideia de ordenar devidamente as coisas para que tenham duração, pois dessa forma é possível conquistar graus cada vez mais altos de estabilidade e segurança, ao mesmo tempo em que é possível garantir aos indivíduos seus direitos individuais. Espinoza (1973) explica que, para que as coisas tenham duração, é necessário ordená-las de tal modo que, ao longo do tempo, se tornem estáveis. Para Foucault (2008): 
O público, noção capital no século XVIII, é a população considerada do ponto de vista das suas opiniōes, das suas maneiras de fazer, dos seus comportamentos, dos seus hábitos, dos seus temores, dos seus preconceitos, das suas exigências, é aquilo sobre o que se age por meio da educação, das campanhas, dos convencimentos. A população é, portanto, tudo o que vai se estender do arraigamento biológico pela espécie à superfície de contato oferecida pelo público" (FOUCAULT, 2008. p. 98-99).

Tanto a Medicina Social quanto a Saúde Pública são produtos de práticas sociais que têm como finalidade a organização de uma relação política entre Estado, indivíduo e sociedade, na qual o sujeito constituinte - a multitude - é caracterizado como aquilo que está ausente, cabendo ao Estado a prática constitutiva da experiência política. Machado et al.(1978) expressam de forma clara a posição do coletivo na Medicina Social e na Saúde Pública enquanto objeto que deve sofrer a intervenção do Estado, no sentido de ser marcado e modelado.

O coletivo-grupo aparece na saúde a partir das discussóes sobre a ideia de determinação social. $\mathrm{O}$ processo saúde-doença é entendido como fenômeno coletivo e fato social, devendo ser analisado tendo como foco os indivíduos agrupados (BARROS, 2007; CASTEL, 1987; LAURELL, 1983). Compreender o processo saúde-doença na sua historicidade, ou seja, como socialmente determinado, implicaria prestar atenção no grupo, composto por um conjunto de indivíduos. Do ponto de vista dos teóricos reformistas que afirmavam o materialismo histórico, essa era a perspectiva adotada para pensar o coletivo. Trata-se de um ponto de vista grupalista, que entende o coletivo como campo estruturado de práticas sociais e sanitárias historicamente determinadas, onde o grupo aparece como espaço de estruturação de intercâmbios e de estabelecimento de laços sociais. O problema dos grupos é que eles se configuram como uma instituição (BARROS, 2007): a partir dessa estrutura, modos de se relacionar são organizados, tomando como ponto de partida a análise da sua dinâmica de funcionamento, a partir da utilização de leituras da realidade que partem de um modelo de compreensão dinâmico, mas que tem base nas teorias do indivíduo.

Já a definição do coletivo como sociedade ganha novos contornos e se torna mais articulada no cenário das reformas sanitárias italiana e brasileira. Foi ficando evidente que a noção de sociedade civil atravessava tanto a experiência italiana quanto a brasileira de reformas sanitárias (BERLINGUER, 1987; 1988; CEBES, 1977a; 1977b; 1977c; 1977d; 1978; 1980a; 1980b), contribuindo para instituir uma nova imagem para o coletivo no território da saúde. O coletivo-sociedade- 
civil talvez seja a forma mais intrigante na atualidade, porque sua origem está situada HEGASTE A no interior dos movimentos sociais e consiste na principal aposta para expressar a noção de coletivo na saúde. Percebemos que a sociedade civil pode ser entendida como o conjunto de interesses privados que adquire uma identidade unitária e específica (HARDT, 2001; HARDT; NEGRI, 2004). Sua missão consiste em equacionar os interesses privados e públicos, através do uso da estratégia de educar a população ou de formar uma consciência que adquire um juizo de valor de algo justo. Ao incentivar a formação de uma unidade homogênea e de caráter identitário, a sociedade civil se institui funcionando como o correlato necessário ao próprio Estado, espaço no qual a razão de Estado se efetua.

Ao problematizarmos essas variações das imagens do coletivo na saúde, percebemos que a potência dessa expressão está na sua possibilidade de variar, e não nas variações que institui. Com isso, produziu-se um outro modo de pensar o coletivo na saúde: a discussão das formas do coletivo, que serviu para evidenciarmos os efeitos de cada um desses modos de entender essa expressão foi deixada de lado, para que a pesquisa se voltasse à análise das intensidades desse conceito na saúde.

É a originalidade do coletivo como força ordinária, indeterminada e inespecífica que parece ser o aspecto mais importante a ser destacado na transição entre o público e o social para o coletivo, característica pouco estudada, talvez porque não percebida em sua amplitude pelos teóricos da Saúde Coletiva. Dessa discussão, emergiu a ideia do coletivo como potência, entendida enquanto noção que coloca em evidência a dimensão intensiva desse conceito na saúde. Enquanto recurso teórico, a variação possibilitou não sermos capturados pela tendência de considerar o coletivo como algo pré-constituído, formado ou acabado, instituído. A ideia de variação nos ajuda a olhar essa expressão como inacabada, enquanto processo ou força movente, como algo inespecífico, porque sem o registro de um significado pré-constituído que o determina.

O que significa tomar a noção de coletivo como potência ou processualidade? Significa entendê-lo como força constituinte, ou seja, como aquilo que marca uma ruptura, desestabilizando as formas instituídas. A estabilidade e o equilíbrio são perspectivas contrárias àquilo que o coletivo, tomado como expressão da potência, introduz no território da saúde. Quando a potência do coletivo varia, impõe uma força que faz escapar as imagens do coletivo, transbordando a potência 
cristalizada nessas imagens, em função da fixação de cada uma dessas formas nas suas dinâmicas constitutivas. Quando se produz uma ruptura no jogo de combinações que faz com que o coletivo se mantenha fixado nas suas imagens, ocorre uma variação, cujo destino é da ordem do devir.

Com o atributo da variação, pensamento, desejo e resistências são derivações de uma relação constitutiva que envolve a composição de noções comuns e a imaginação. Portanto, variar é a potência singular do coletivo na saúde. A produção de um estranhamento do coletivo instituído permitiu o seu deslocamento para um plano móvel, processual e da ordem da potência. Nos cenários reformistas, parece ser essa dimensão sensível que coloca em movimento o pensamento, adensando o desejo e as práticas de caráter inventivo no território da saúde. A variação do coletivo como potência coloca em evidência o desenrolar de um fluxo ininterrupto que conduz ao aumento ou à diminuição da capacidade de agir e da força de existir de novas ideias na saúde.

Assim, afirmamos um ponto de vista no qual a natureza do coletivo na saúde é a própria ideia de variação da potência. Enquanto o coletivo instituído é um processo constante de recombinação e redistribuição de relações que têm como pressupostos a estabilidade e o equilíbrio, o coletivo potência é a dimensão processual da variação, quantidade intensiva, força móvel e instituinte. Resta perguntar como essa força móvel se expressa nos cenários reformistas conduzindo à composição da Saúde Coletiva, e que tipo de questôes essa perspectiva de análise coloca na atualidade.

\section{A potência do coletivo-inespecífico na saúde}

O segundo argumento do nosso estudo foi obtido revisando a construção histórica da Saúde Coletiva, tendo como base os autores que discutiram a formação desse saber no cenário brasileiro (MERHY, 1987; FLEURY TEIXEIRA, 1992; COSTA, 1992; COHN, 1992; NUNES, 2003; 1992; 1994; 1998; PAIM; ALMEIDA FILHO, 1998). Revisitando o cenário reformista, encontramos uma pista para pensar o coletivo como inespecífico, seguindo a direção de análise dessa expressão como potência. Dada a dificuldade dos teóricos da época de definir o coletivo, os textos da época afirmavam essa expressão como algo vago ou difuso, como inespecífica. 
Com Espinoza (1973), foi possível compor um plano epistemológico distinto para compreender a noção de coletivo potência no território da saúde, tomando como base a ideia de inespecífico atribuída a essa expressão pelos teóricos brasileiros. Como a potência é móvel, força de existir e de produzir e força de pensar e de compreender, foi possível intuir que a ideia de inespecífico continha essas características. Enquanto o coletivo instituído aparecia cristalizado no plano das formas, a processualidade da potência era capturada e substituída por imagens, forjando uma identidade bem definida para essa expressão no território da saúde. Por outro lado, enquanto inespecífico, a força do coletivo como potência seguia o seu destino, qual seja, a variação.

Problematizar o coletivo como algo vago ou difuso, ou seja, a forma como era entendido no discurso dos teóricos da Saúde Coletiva no cenário reformista, permitiu inventar um novo lugar para o inespecífico, com força para caracterizar essa expressão como potência. Essa torção permitiu avançar o estudo do coletivo na saúde, entendendo como inespecífico a potência de variar do coletivo e sua capacidade de operar no campo problemático das reformas sanitárias italiana e brasileira.

Entender o coletivo como potência significa prestar atenção na processualidade constituinte, aquilo que põe em movimento ou que age produzindo a crise nos territórios constituídos, que é da ordem do inespecífico e da variação. Um projeto genealógico-cartográfico que evidencia a maneira como o coletivo agia instituindo a crise, fazendo com que o território da saúde se desterriorializasse ou perdesse sentido, para que novas experiências singulares fossem inventadas. Prestar atenção na processualidade aberta pela variação do coletivo como potência na saúde implica perceber que a ideia do inespecífico sustenta uma tensão no campo da saúde, uma vez que a identidade do coletivo ainda não está caracterizada. Sob esse ponto de vista, a inespecificidade do coletivo, ao contrário de significar um vazio de sentido, pode ser compreendida como um espaço carregado de potência, uma vez que é sobre esse plano que diferentes forças disputam e cooperam para a construção das singularidades. É a dimensão constituinte que o coletivo como potência faz aparecer na saúde que nos interessava acompanhar nos campos problemáticos italiano e brasileiro.

Os autores da Saúde Coletiva afirmam que a Saúde Pública sempre considerou o coletivo como área de enfoque na saúde (MERHY, 1987; COHN, 1992). A 
Saúde Coletiva se instituiu pela junção da Medicina Social e da Saúde Pública, sendo que, ao substituir a noção de "social" pela de "coletivo", este último tornava-se mais inespecífico, exigindo que fosse rastreado em sua totalidade (COHN, 1989). Mas a Saúde Coletiva não pode ser pensada enquanto um processo natural de evolução do conceito de Saúde Pública ou de Medicina Social, pois sua construção adquiriu sentido num contexto histórico específico e no jogo de lutas introduzido pelos movimentos reformistas. Muitas foram as dificuldades para definir ou compreender os sentidos do coletivo na saúde. Se a ideia de coletivo como inespecífico aparecia naquele momento como um não lugar caracterizado por certa fragilidade conceitual, foi a partir dessa pista que percebemos a importância do coletivo como inespecífico na saúde, bem como a potência desse modo de expressão nos cenários reformistas.

Tomando a característica constituinte do inespecífico e sua relação com a ideia de coletivo como potência, resta-nos analisar as implicaçôes dessa expressão para a Saúde Coletiva, bem como a maneira como o inespecífico foi produzindo sentido ou sendo concatenado na experiência italiana e na brasileira. Em outras palavras, a questão pode ser enunciada da seguinte forma: como a potência do coletivo aparece nos dois cenários estudados? Já não é mais a fixação do coletivo nas formas que lhe são tradicionalmente atribuídas que interessa, mas a força que o caracteriza como algo inespecífico ou sem rosto, entendido como ponto de saturação que representa o mais alto grau de expressão da potência.

Partindo de Berlinguer (1987; 1988), Maccacaro (1973; 1976a; 1976b; 1972; 1970) e Basaglia (2001), a imersão no cenário italiano e os encontros com os interloucutores no percurso da pesquisa nos ajudaram a entender a cartografia do coletivo como inespecífico na experiência italiana. Berlinguer $(1987 ; 1988)$ foi particularmente importante no contexto brasileiro de reforma sanitária, pois influenciou os reformistas brasileiros. Entretanto, a discussão que trouxe para o Brasil representa um recorte das agitações que se produziram na Itália no período estudado.

Com a crítica ao funcionamento das instituições que representavam a sociedade, ou seja, sua posição de mediadoras das forças sociais, organizouse um processo histórico que ativou mudanças profundas na Itália. A partir dos anos 1950, uma experiência de agitação entre os operários foi inventada, tornando-se um movimento no sentido da construção de um senso de direção 
para a sociedade, extrapolando o ambiente restrito da fábrica. Esse cenário colocava um problema intensivo: ou os operários eram capturados pelas forças que antecipavam um sentido para as agitações operárias, como era o caso dos partidos políticos e dos sindicatos, que definiam as agitaçôes antes mesmo de produzirem seus efeitos; ou forjavam uma experiência nova, que colocava em cena a processualidade constituinte, abrindo a possibilidade para o devir e para a invenção de novas singularidades.

A análise da experiência italiana permitiu perceber que Maccacaro e Berlinguer sustentavam posições distintas. O primeiro propunha uma Medicina renovada e subversiva, uma revolução no saber médico, enquanto o segundo tinha características reformistas. Foi Berlinguer quem influenciou os reformistas brasileiros, sendo que um conjunto de questóes importantes para entender o coletivo na saúde acabaram não sendo problematizadas no cenário brasileiro.

$\mathrm{Na}$ segunda metade do século XX, produziu-se na Itália um modo de tomar a saúde pelos operários que levou à constituição de um saber denominado "saúde operária”, pensamento que carregava uma força problematizadora, fazendo o território da saúde entrar em crise. Tratava-se de uma apropriação da saúde pelo movimento operário italiano, que criticava o processo de medicalização produzido pela ciência médica, destacando o problema da antecipação do sentido, através de uma operação sobre a imaginação. Com a valorização da racionalidade técnica e a objetivação do doente, produzia-se a naturalização do sofrimento. Produção de um saber sobre a saúde operária, que colocava em questão a dinâmica de composição da realidade, não como uma visão de conjunto, mas como a expressão de saberes multissituados que explicitavam a dimensão processual, o coletivo como inespecífico e variação.

Tratava-se de um conhecimento de Saúde Coletiva. A preocupação dessa Saúde Coletiva, que deve ser definida como um saber sem rosto, era de funcionar como conhecimento operativo, afirmando a força de existir do operário enredado numa engrenagem, enquanto nó de uma rede. Ora, esse operário não era apenas o trabalhador da fábrica, mas aquele que derivava de cada um de nós, uma multiplicidade de singularidades em agitação. Tratava-se de desestabilizar certo modo de pensar o coletivo como imagem na saúde, no sentido da composição de um saber em ruptura com o conhecimento em saúde do período, influenciado pela Medicina Social e pela Saúde Pública. Uma pista dos operários italianos 
para pensar a Saúde Coletiva é a potência que esse saber adquiriu para explicitar a trama constitutiva da realidade, deixando evidente a sua dimensão intensiva e a posição do coletivo como inespecífico.

Na saúde operária, a imaginação e a composição de noções comuns produziam desterritorialização, agitando o pensamento e concatenando agenciamentos que caracterizavam o coletivo como inespecífico, momento no qual a potência se expressava, variando. $\mathrm{O}$ que se produz a partir dessa experiência é um deslocamento do indivíduo como eixo central do saber médico, o povoamento do território da saúde por uma multiplicidade de singularidades, que pode ser percebida a partir da ideia de "operários em atividade". No lugar de um saber médico, se organiza um conhecimento operário sobre a saúde que colocava o território da Medicina Social e da Saúde Pública em crise, efetuando a potência do coletivo. É a Saúde Coletiva como força de desterritorialização, um não saber ou um saber sem rosto que se expressava na Itália naquele período.

$\mathrm{O}$ que chamou a atenção dos reformistas brasileiros na experiência italiana foi essa singularidade do coletivo, percebida de forma intuitiva. Talvez por essa razão os teóricos tivessem dificuldades para definir essa expressão naquele período, preferindo deixá-la como algo vago ou difuso, porém carregado de potência. A sensação era de que não havia necessidade de precisar aquilo que o coletivo como potência engendrava no território da saúde, porque as pessoas estavam vivendo essa agitação, que se expressava como atividade. O coletivo, em vez de ser deduzido, efetuava-se como força instituinte, disparando a processualidade constituinte, atributo da variação, que conduz à invenção de outros possíveis para a saúde.

Mas o percurso escolhido pelos reformistas brasileiros seguiu na direção do ordenamento dessa força, instituindo no plano do conhecimento aquilo que havia sido provocado pela variação do coletivo: a necessidade de tornar específico o inespecífico, transformar a fragilidade desse não lugar, povoá-lo (COHN, 1989). Concepção que ganhava força na medida em que o movimento sanitário, em sua conformação, falava de uma classe operária em agitação que não aparecia no cenário político brasileiro dos anos 1970. Sem contar com a participação direta da classe trabalhadora, o discurso e a prática do movimento sanitário era feito para uma classe ausente, por ela ou para ela (ESCOREL, 2009). Esse movimento significou a institucionalização de uma imagem do coletivo, ou seja, uma forma determinada que encontrou no discurso de Berlinguer $(1987 ; 1988)$ o 
seu fundamento. A influência de Berlinguer advinha de um momento no qual as

agitações em torno de um pensamento em Saúde Coletiva já perdiam consistência e um modelo de reforma sanitária se instituía na Itália. No Brasil, esse processo se dá em função de um movimento dos trabalhadores da saúde, que se ocuparam de fazer aparecer uma classe operária que não existia enquanto tal.

Ao contrário, tomado enquanto inespecífico, o coletivo significava a possibilidade de manter ativo o atributo da variação no território da saúde, condição de emergência da Saúde Coletiva no contexto brasileiro, eixo de afirmação de uma política diferente no território da saúde. Portanto, o que parece ser importante sublinhar é a força que a potência do coletivo tem de se mover e, ao mesmo tempo, colocar o pensamento em movimento, abrindo a possibilidade para um conhecimento em devir, diferente da Medicina Social e da Saúde Pública no contexto brasileiro.

Com isso, definimos a característica singular da noção de coletivo na saúde, que fornece uma pista importante para estabelecer a diferença entre Medicina Social/Saúde Pública e Saúde Coletiva. É o coletivo como potência, força inespecífica e de variação a característica mais importante do coletivo na saúde. Uma vez definido que a força do coletivo como inespecífico é a questão-chave para entender a invenção da Saúde Coletiva, perguntamos como essa potência induzia rupturas.

O coletivo enquanto representação varia nas imagens de população, grupo ou sociedade civil na saúde. A análise dessas variaçōes do coletivo permite situar essa expressão em campos do conhecimento que há muito são utilizados no território da saúde, como, por exemplo, a Medicina Social e a Saúde Pública. Enquanto potência, a questão do coletivo é a variação e o inespecífico, sendo que essa marca parece ser a singularidade da Saúde Coletiva. Ao colocarmos a noção de coletivo em evidência, percebemos que é bem possível que se atualize na Saúde Coletiva o modelo da Saúde Pública e da Medicina Social, especialmente se não tivermos a capacidade de compreender a singularidade inventada para essa expressão nas experiências reformistas, consoante àquilo que vimos com a experiência italiana e com as formulações que marcaram os primórdios da Saúde Coletiva no contexto brasileiro, quando o coletivo como inespecífico ainda se sustentava. Ao ser rastreado, o coletivo se institui, passando a assumir as formas ou imagens que lhe são tradicionalmente atribuídas no território da Medicina Social e da Saúde Pública. 
A atualização da Saúde Pública e da Medicina Social "por dentro" da Saúde Coletiva é uma força revestida de novos mecanismos de controle, que opera pela captura dos sentidos e cuja tendência é conservar aquilo que está instituído. Quando utilizamos as imagens do coletivo na saúde, ou seja, quando privilegiamos as formas do coletivo em detrimento da afirmação dessa expressão como variação, que se expressa quando tomamos essa noção como inespecífico, esquecemos da sua singularidade na saúde, sendo possível ver se sustentar um projeto político que se aproxima do modo como a Medicina Social e a Saúde Pública entendem o coletivo.

A saída desse circuito parece estar na desterritorialização das imagens do coletivo na Saúde Coletiva para fazer aparecer o inespecífico. Nesse momento, o inespecífico, que num primeiro momento podia ser confundido com algo confuso, irrelevante ou sem sentido, expressa-se enquanto positividade. Ao instaurar a crise em função da saturação das imagens do coletivo instituído na saúde, faz aparecer o jogo da variação, produzindo rupturas no pensamento, agitando o desejo e produzindo resistências.

Foi a condição de inespecífico do coletivo, combustível das agitações e dos movimentos instituíntes do período, que garantiu as condições para que a Saúde Coletiva fosse inventada. Por essa razão, a Saúde Coletiva não pode ser pensada como o começo de um saber sobre o coletivo no território da saúde; é a força do coletivo como inespecífico, bem como a sua potência de variar, que colocaram as condiçôes para o surgimento da Saúde Coletiva. E essa é a singularidade do coletivo na saúde. É preciso perceber que as imagens do coletivo impedem que nos aproximemos da força do coletivo como potência na saúde, fazendo com que essa expressão seja tomada como algo homogêneo ou como conjunto representado.

\section{Sobre a estratégia de investigação}

A estratégia de investigação adotada foi tomando forma na medida em que o estudo avançava. Se, num primeiro momento, o trabalho tinha uma conotação de pesquisa-intervenção (ROCHA, 2003), na medida em que a noção de coletivo como potência ganhava fôlego, a estratégia de produção do conhecimento adotada mudava de sentido/direção, pois se tratava, antes, de cartografar uma situaçãoproblema: o que era e como se expressava o coletivo na saúde. A análise genealógica da noção de coletivo no território da saúde fez aparecer o movimento da potência, 
entendida como a característica constituinte da Saúde Coletiva, na qual o coletivo assumia posição de destaque. Um conhecimento articulado com a vida, parcial e voltado para a expansão da potência. A noção de coletivo já não se expressava mais como uma forma ou uma imagem, mas enquanto variação, como força movente.

A genealogia (FOUCAULT, 2005a; 2005b) é uma estratégia de investigação que opera produzindo a realidade, e, por isso, não permitia antecipar um caminho para nossa pesquisa. O importante era voltar a atenção para o movimento de construção do problema, sendo que o método foi tecido e ganhava consistência exatamente nessa processualidade, adquirindo sentido na medida em que o coletivo era problematizado. A estratégia genealógica forneceu elementos para compreender o acontecimento singular que conduziu à invenção da Saúde Coletiva nos campos problemáticos instaurados pelas reformas sanitárias italiana e brasileira. Ao avançarmos na análise do coletivo na saúde, constatamos a necessidade de construir um plano conceitual diferente para pensar essa expressão. Ao definirmos o coletivo como potência, havia a necessidade de fazer aparecer um campo intensivo nos cenários reformistas italiano e brasileiro, para entender a relação da potência com a invenção da Saúde Coletiva. Nesse momento, a cartografia passou a funcionar como estratégia de produção do conhecimento (ZAMBENEDETTI; SILVA, 2011), pois estava em jogo fazer aparecer o plano intensivo do coletivo, o movimento da variação e o inespecífico.

Para a análise dos campos problemáticos das reformas sanitárias, utilizamos recursos da pesquisa documental, observação participante e entrevistas abertas com informantes-chave que vivenciaram o período histórico analisado. O diário de campo foi utilizado para registro das experiências. Os dados que coletamos dos documentos, das entrevistas e das observações foram integrados à escrita do texto. $\mathrm{O}$ estilo da escrita escolhido não foi trazer as falas das pessoas com as quais conversamos ou os conteúdos dos documentos e interpretá-los, mas fazer aparecer as relaçóes daquilo que nossos interloucutores disseram sobre as experiências reformistas com o problema estudado. A proposta foi realizar uma discussão epistemológica muito mais do que explorar ou discutir as experiências vividas.

Apostamos em analisar a constituição da noção de coletivo na saúde com a finalidade de fazer aparecer um território diferente de pesquisa e novos problemas a serem enfrentados, entre eles: como sustentar uma política do inespecífico para a expressão do coletivo na saúde, a fim de disparar as variações que conduzem ao 
surgimento de novas singularidades? Como pensar um campo de lutas "coletivo", sem que esse "coletivo" pareça um amontoado de fragmentos no cenário atual da saúde? Como pensar um campo de lutas coletivo, quando o que está colocado no território da saúde tende à fragmentação das lutas?

\section{Considerações finais}

Ao colocarmos em análise a questão do coletivo na saúde, perguntamos quais as potências da Saúde Coletiva no cenário atual e, da mesma forma, abrimos outro caminho de reflexão e pesquisa nesse campo do conhecimento. Com a problematização das formas do coletivo, adentramos o plano da variação, onde essa noção pode ser discutida como processualidade. A ideia de inespecífico, que antes fora tomada de forma banal, adquiriu uma dimensão operativa e não substancializada, rompendo com a tendência de afirmar o coletivo na saúde como imagem que sustenta a dicotomia indivíduo-sociedade. Perguntamo-nos: será que as formas atribuídas ao coletivo não reproduzem na Saúde Coletiva, paradoxalmente, os conteúdos da Medicina Social ou da Saúde Pública, engendrando um cenário no qual a potência é capturada?

A invenção da Saúde Coletiva não pode ser atribuída apenas à ampliação do conceito de saúde, pois o coletivo, tomado enquanto inespecífico e força de variar, parece ter sido ingrediente importante nesse processo. Desse modo, com a análise do coletivo e tomando como ponto de partida o campo problemático instaurado pelas agitaçóes reformistas italiana e brasileira, deslocamos o eixo que estrutura a Saúde Coletiva no cenário brasileiro, com o intuito de promover uma torção nesse saber. Tratava-se de transformar o coletivo numa ferramenta, subvertendo a visão hegemônica que se afirma na Saúde Coletiva ao afirmar essa noção como população, grupo ou sociedade civil.

A potência do coletivo precisa ser o tempo todo buscada; ela não está dada de antemão. Dessa forma, o problema do coletivo na saúde é uma questão de abertura de um horizonte possível, ainda não povoado, sem rosto: imersão num plano de intensidades que coloca a possibilidade da invenção. Quando o coletivo é tomado na sua processualidade instituinte, a Saúde Coletiva passa a ser entendida como dispositivo de efetuação do coletivo como potência, enquanto um saber intensivo. Esse saber pode tanto mais quanto maior for a potência do coletivo 
de variar no território da saúde. É isso que a experiência italiana e a brasileira mostraram quando problematizamos a noção de coletivo. Quando o coletivo se torna inespecífico na saúde, a Saúde Coletiva se constitui como um dispositivo de efetuação dessa potência, desterritorializando aquilo que está instituído, abrindo espaço para o devir e para a expressão de uma política não identitária ou de um conhecimento que afirma a singularidade da Saúde Coletiva. A tríade inespecífico-variação-intuição produz a passagem do plano das formas do coletivo para a análise da dimensão processual e intensiva dessa expressão, afirmando o devir no território da saúde. ${ }^{1}$

\section{Referências}

BARROS, RB. Grupo: a afirmação de um simulacro. Porto Alegre: Ed. Sulina/UFRGS, 2007.

BASAGLIA, F. A instituição negada. 3a ed. Rio de Janeiro: Graal, 2001.

BERLINGUER, G. Medicina e política. $3^{\text {a }}$ ed. São Paulo: Hucitec, 1987.

. Uma reforma para a saúde. In: BERLINGUER, G.; TEIXEIRA, S.F.; CAMPOS,

G.W de S. (Org.). Reforma Sanitária: Itália e Brasil. São Paulo: Hucitec, 1988. p. 1-106.

CASTEL, R. A gestão dos riscos: da antipsiquiatria à pós-psicanálise. Rio de Janeiro: Francisco Alves, 1987.

CEBES. Editorial. Revista Saúde em Debate, n. 1, 1977a. . Editorial. Revista Saúde em Debate, n. 2, 1977 b. . Editorial. Revista Saúde em Debate, n. 3, 1977c. . Editorial. Revista Saúde em Debate, n. 4, 1977d. . Editorial. Revista Saúde em Debate, n. 7-8, 1978. . Editorial. Revista Saúde em Debate, n. 9, 1980a. . Editorial. Revista Saúde em Debate, n. 10, 1980 b.

COHN, A. Conhecimento e prática em Saúde Coletiva: o desafio permanente. Saúde e Sociedade, v. 1, n. 2, p. 97-109, 1992. . Caminhos da Reforma Sanitária. Lua Nova, n. 19, p. 123-140, 1989.

COSTA, N.R. Ciências sociais e saúde: consideraçôes sobre o nascimento do campo da saúde coletiva no Brasil. Saúde em Debate, v. 36, p. 58-65, 1992.

DELEUZE, G. Espinoza: filosofia prática. São Paulo: Escuta, 2002a. . Cosa può un corpo? Lezioni su Spinoza. 2a ed. Verona: Ombre Corte, 2010. . Spinoza e il problema dell'espressione. $4^{\mathrm{a}}$ ed. Macerata: Quodilibert, 2014. 
DONNANGELO, M.C.F. Saúde e sociedade. São Paulo: Duas Cidades, 1976.

. Medicina e sociedade: o médico e seu mercado de trabalho. São Paulo: Pioneira, 1975.

ELIAS, P.E. Análises sobre a reforma sanitária e concepções políticas subjacentes: a visão autoritária do ideário progressista. Saúde e Sociedade, v. 2, n. 1, p. 59-73, 1993.

ESCOREL, S. Reviravolta na saúde: origem e articulação do movimento sanitário. Rio de Janeiro: Fiocruz, 2009.

ESPINOZA, B. Ética. Coleção os Pensadores. São Paulo: Abril, 1973.

. Tratado político. São Paulo: Martins Fontes, 2009.

FLEURY TEIXEIRA, S. As ciências sociais em saúde no Brasil. In: NUNES, E. As ciências sociais em saúde na América Latina. Brasilia: OPAS/OMS, 1985.

. O dilema reformista na reforma sanitária brasileira. Revista de Administração Pública, v. 21, n. 4, p. 94-115, 1987.

. (Org.). Saúde coletiva? Questionando a onipotência do social. Rio de Janeiro:

Relume-Dumará, 1992.

FOUCAULT, M. O nascimento da Medicina Social. In: FOUCAULT, M. Ditos \& Escritos VII: Arte, epistemologia, filosofia e história da medicina. Rio de Janeiro: Forense Universitária, 2011a, p.402-424.

. A extensão social da norma. In: . Ditos \& Escritos VII: Arte, epistemologia, filosofia e história da medicina. Rio de Janeiro: Forense Universitária, 2011b, p.394-398.

A política da saúde no século XVIII. In: . Ditos \& Escritos VII: Arte, epistemologia, filosofia e história da medicina. Rio de Janeiro: Forense Universitária, 2011c, p.357-373.

As grandes funçôes da Medicina em nossa sociedade. In: Ditos \& Escritos VII: Arte, epistemologia, filosofia e história da medicina. Rio de Janeiro: Forense Universitária, 2011d, p.305-306.

. Nietzsche, a genealogia, a história. In: . Ditos \& Escritos II: arqueologia das ciências e história dos sistemas de pensamento. Rio de Janeiro: Forense Universitária, 2005a, p.260-281.

. Segurança, território, população. São Paulo: Martins Fontes, 2008.

. Sobre as maneiras de escrever a história. In: - Ditos \& Escritos II: arqueologia das ciências e história dos sistemas de pensamento. Rio de Janeiro: Forense Universitária, 2005b. p. 62-77.

HARDT, M. O enfraquecimento da sociedade civil. 2001 / mimeo/

HARDT, M.; NEGRI, A. Império. Rio de Janeiro: Record, 2004.

LAURELL, A. C. A saúde-doença como processo social. In: NUNES, E. D. Medicina Social: aspectos históricos e teóricos. São Paulo: Global, 1983, p. 133-158. 
LUZ, M.T. Notas sobre a política de saúde no Brasil de "transição democrática” - anos 80. Saúde em Debate, v. 32, p. 27-32, jun. 1991.

MACCACARO, G.A. L'unità sanitaria locale come sistema (1976b). In: . Medicina e Potere: per una medicina da rinovare. Scritti 1966-1976. Milano: Feltrinelli, 1979.

Medicina Democratica, movimento di lotta per la salute (1976a). In:

Medicina e Potere: per una medicina da rinnovare. Scritti 1966-1976. Milano: Feltrinelli, 1979. Prática médica e controle social (1970). In: Medicina e Potere: per una medicina da rinnovare. Scritti 1966-1976. Milano: Feltrinelli, 1979.

Classe e salute (1973). In: Medicina e Potere: per una medicina da rinnovare. Scritti 1966-1976. Milano: Feltrinelli, 1979.

. L'uso di classe della medicina (1972). In: Medicina e Potere: per una medicina da rinnovare. Scritti 1966-1976. Milano: Feltrinelli, 1979.

MACHADO, R. et. al. Danação da norma: Medicina Social e constituição da psiquiatria no Brasil. Rio de Janeiro: Graal, 1978.

MERHY, E.E. O capitalismo e a Saúde Pública. 2.ed. São Paulo: Papirus, 1987.

NEGRI, A. Cinco liçôes sobre Império. Rio de Janeiro: DP\&A, 2003.

. A anomalia selvagem: poder e potência em Spinoza. Rio de Janeiro: Editora 34, 1993.

. O poder constituinte: ensaio sobre as alternativas da modernidade. São Paulo:

DP\&A, 2002.

NUNES, E. D. A sociologia da saúde nos Estados Unidos, Grã-Bretanha e França. Saúde e Sociedade, v. 8, n. 1, p. 9-95, 2003.

. As Ciências Sociais em saúde: reflexôes sobre as origens e a construção de um campo de conhecimento. Saúde e Sociedade, v. 1, n. 1, p. 59-84, 1992.

Saúde coletiva: história de uma ideia e de um conceito. Saúde e Sociedade, v. 3, n.

2, p. 5-21, 1994.

. Saúde Coletiva: história e paradigmas. Interface: Comunicação, Saúde e Educação, v. 3, p. 107-116, 1998.

PAIM, J.S.; ALMEIDA FILHO, N. Saúde coletiva: uma "nova Saúde Pública" ou campo aberto a novos paradigmas? Revista de Saúde Pública. São Paulo, n. 32, v. 4, p. 299-316, 1998. ROCHA, M. L. Pesquisa-intervenção e a produção de novas análises. Psicologia, Ciência e Profissão, v. 23, n. 4, p. 64-73, 2003

ZAMBENEDETTI, G; SILVA, R.A.N. Cartografia e genealogia: aproximações possíveis para a pesquisa em psicologia social. Psicol. Soc. [online], Florianópolis, v. 23, n. 3, p. 454-463, dez. 2011. Disponível em: <http://www.scielo.br/scielo.php?script=sci_ arttext\&pid $=$ S0102-71822011000300002\&lng=en \&nrm=iso >. Acesso em: 7 jun. 2015. 


\section{Nota}

${ }^{1}$ C. F. Guimarães trabalhou na estruturação do artigo, delineamento do método, coleta de dados e análise dos resultados, assim como na redação do artigo. R. A. N. da Silva contribuiu na concepção do projeto de tese, na discussão da metodologia e da análise dos dados, bem como na discussão e redação final do artigo. 
Transformations and intensities of the collective in Colletive Health

In this article, we discuss Collective Health, in order to monitor how it is expressed and which senses updates. We place our research in a genealogical perspective, analyzing the composition and loss of sense of reformist territories in Italian and Brazilian scenarios. We discussed the images to express the collective health - the people, the group and civil society - to propose a different way of thinking that expression, of procedural and intensive character as a power. It is not the setting of this notion to assigned shapes that makes Collective Health, but the strength that characterizes the collective as something unspecific, power variation. Considering the uniqueness of the collective prevents that paradoxically, one reproduces a policy that affirms the precepts of Social Medicine or Public Health in the field of Collective Health, opening up the possibility for new productions of meaning.

Key words: collective; Collective Health; epistemology; genealogy; healthcare reform. 